\title{
Uma crítica lésbico-feminista ao discurso transgênero
}

\section{Gender hurts: a feminist analysis of the politics of transgenderism.}

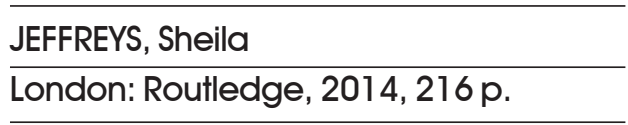

Com uma rapidez surpreendente, a temática "transgênero" ganhou espaço na mídia, na academia e mesmo na lei. Reportagens sobre o assunto são frequentes em jornais, revistas e televisão. Em curto espaço de tempo, a maior parte dos países ocidentais concedeu direitos como troca do nome civil e dos documentos de identificação, quando não tratamento para a chamada "mudança de sexo" na rede pública de saúde. E é cada vez mais difícil participar de uma mesa sobre direitos reprodutivos, por exemplo, sem que alguém da plateia faça uma pergunta sobre o direito dos homens ao aborto significando pessoas nascidas mulheres, não operadas, mas que optaram por uma identidade do sexo masculino.

A simpatia que, nos círculos mais progressistas, cerca as reivindicações dos transgêneros faz com que exista muito pouca crítica a seus pressupostos e sua prática. É essa crítica que Sheila Jeffreys busca desenvolver em Gender hurts, seu novo livro. Jeffreys, uma teórica e militante feminista lésbica australiana, não hesita em adotar um tom abertamente provocativo em suas obras, como Beauty and misogyny (Routledge, 2005), uma ácida denúncia dos efeitos da imposição do padrão de beleza feminino, e Anticlimax (The Women's Press, 1990), que vê a revolução sexual dos anos 1960 e 1970 levando à ampliação da objetificação das mulheres. Gender hurts não foge à regra e, mais do que polêmico, chega a ser agressivo em alguns momentos.

Tal agressividade aparece, na narrativa de Jeffreys, como uma reação ao que ela apresenta como sendo o boicote dos promotores da transgeneridade contra seus críticos. O rótulo "transfóbico" é aplicado a qualquer um que questione os fundamentos ou as práticas da corrente. Jeffreys relata que aqueles que manifestam ressalvas são alvo de pesadas campanhas difamatórias e sofrem diversas represálias, perdendo acesso a eventos, publicações e mesmo postos acadêmicos. Como poucos se dispõem a arcar com esse ônus, boa parte da reflexão crítica sobre o tema estaria confinada a blogs assinados por pseudônimos. Da forma como a autora descreve a situação, nos ambientes intelectuais de esquerda a transgeneridade teria se tornado um consenso bem-pensante, inquestionável, sob pena de exclusão.

No entanto, há muito a ser discutido no discurso da transgeneridade, a começar pelo fato de que, na contramão da maior parte da reflexão feminista, ele pressupõe uma valorização dos papéis de gênero. A noção de que alguém sente seu sexo biológico como inadequado, uma vez que sua psicologia e seu comportamento correspondem ao gênero oposto, apresenta gênero como uma essência, como um ponto fixo e objetivo. Trata-se de algo que já está presente nas formulações da teoria queer, pesadamente criticada por Jeffreys, e em particular na obra de Judith Butler. A teoria queer cria "uma política de gênero que reduz gênero a uma forma de expressão pessoal ou performance e obscurece as relações materiais de poder da dominação masculina" (p. 42). A exaltação das performances transgressoras, própria do queer, necessita da permanência 
da associação de mulheres e homens com papéis estereotipados. Quanto mais caminharmos para a sociedade pós-gêneros com que o feminismo tanto sonhou, aquela em que não há nenhum tipo de comportamento predefinido associado a homens ou a mulheres, mais difícil será produzir a "transgressão" valorizada pelo discurso queer. Assim, a teoria e a políica queer participariam "de uma missão de resgate do gênero, contra a campanha feminista radical para aboli-lo" (p. 43).

A transgeneridade, assim, promoveria $\circ$ reforço dos estereótipos. O homem que se sente mulher, portanto desconfortável no próprio corpo, é aquele que quer andar maquiado e de salto alto, mostrar-se frágil e hiperemotivo como se houvesse uma associação natural entre as mulheres e tais comportamentos. Para alguns porta-vozes da transgeneridade, que o livro cita "masculino" e "feminino" seriam, ao menos em parte, "naturais e tanto precedem a socialização quanto suplantam o sexo biológico" (p. 50). Ou seja: o discurso trangênero representaria um recuo em relação à denúncia, presente em toda a história do feminismo, da "feminilidade" como construção ideológica e como instrumento de dominação. Um recuo, sobretudo, em relação ao antinaturalismo que sempre marcou o feminismo como teoria crítica.

No processo, práticas como cross-dressing deixam de ser entendidas como um jogo sexual, voltado à excitação dos praticantes, para serem vistas como reveladoras de uma "identidade" que precisa emergir (p.28). Jeffreys aponta a centralidade dos papéis estereotipados de gênero na produção das fantasias sexuais. Pessoas que não conseguem imaginar sua própria sexualidade sem esse enquadramento se sentiriam ameaçadas com a ideia de uma sociedade pós-gêneros. Fica clara sua concordância de fundo com a visão de Catherine MacKinnon, para quem a sexualidade da nossa sociedade é baseada na erotização da dominação. A valorização dessas fantasias e a incapacidade de imaginar um erotismo que prescinda delas joga a favor da manutenção dos papéis de gênero, logo da própria dominação masculina.

Na leitura de Jeffreys, o trânsito de indivíduos nascidos homens para o papel de "mulheres" é revelador, sobretudo, do desejo masoquista de estar na posição dominada. Já o trânsito na direção inversa, menos frequente, revelaria a vontade de ascender ao que ela chama de "casta sexual superior", optando por uma solução individual no lugar da luta feminista por igualdade (p. 100). A despeito dos preconceitos contra pessoas trans, aparecer como pertencendo ao sexo masculino concederia vantagens palpáveis, numa sociedade sexista como a nossa (do maior respeito nos locais de trabalho ao fim do assédio sexual).

Gays e lésbicas seriam particularmente atingidos com a transgeneridade, na medida em que o desejo de um homem por um homem ou de uma mulher por uma mulher aparece como indício do descompasso entre o sexo biológico e o gênero. A homossexualidade representa o principal desvio da relação sexo/ gênero considerada "saudável" por uma visão tradicional que, no entanto, acaba por ser assumida pela transgeneridade. Antes, tal desvio se corrigia forçando a adequação aos papéis de gênero esperados (obrigando os meninos e homens a comportamentos "masculinos", as meninas e mulheres a comportamentos "femininos"). Agora, ele seria corrigido por meio da modificação do sexo. A transgeneridade dessa forma, seria um discurso de normalização e de adequação às convenções, apoiado também por "gays conservadores que asseveram sua concordância com a masculinidade normativa e procuram negar e excluir gays afeminados, lançando-os na categoria do 'transgênero'" (p. 32).

Jeffreys dá muitos exemplos de como, sobretudo na comunidade médica, mas não só nela, o discurso da transgeneridade pode ser tingido por uma evidente homofobia. É o caso da identificação "precoce" da disfunção de gênero em crianças. Meninos que gostam de brincar de bonecas - ou meninas que não gostam - são apresentados como vítimas de um transtorno de identidade de gênero. $O$ menino que brinca de boneca se torna uma "menina", com nome e posição social associados a essa nova caracterização. Eventualmente, será submetido à "correção" de seu sexo biológico. Na Austrália, a partir dos 10 anos crianças podem ser submetidas a tratamentos para impedir a eclosão da puberdade. Aos 16, recebem hormônios para adquirir as características do sexo oposto e, aos 18, podem partir para cirurgias de amputação genital, isto é, para a "mudança de sexo" (p. 122). Tal violência só é possível sob a égide de uma ideologia que vê os papéis estereotipados de gênero como naturais e absolutos.

É claro que o discurso da transgeneridade não fala de papéis estereotipados, mas de "identidade". Aqui, uma vez mais, Jeffreys aponta um recuo em relação à reflexão 
feminista anterior. A identidade deixa de ser pensada como uma imposição de estruturas opressivas, algo do qual devemos nos libertar, e passa a ser vista como um objeto de consumo. A inadequação aos papéis convencionais de gênero deixa de ser um indício de transformação social para ser "privatizada e despolitizada", como dizem Dwight Billings e Thomas Urban, citados pela autora (p. 39).

A possibilidade de passar de um sexo/ gênero a outro, isto é, de consumir uma ou outra identidade, encarnaria uma liberdade que não é mais a superação dos constrangimentos e dos estereótipos, mas um maior leque de escolhas pré-fabricadas. Ou seja: no campo da sexualidade e do gênero também se verificaria a démarche neoliberal, pela qual a realização humana não resulta mais do desenvolvimento autônomo dos indivíduos, e sim da ampliação das oportunidades de mercado.

Reais oportunidades de mercado surgem, como Jeffreys indica, com uma verdadeira indústria da transgeneridade, que inclui fabricantes de sapatos de salto alto tamanho extragrande, consultores que explicam como as pessoas devem encarnar suas novas identidades e ramos específicos da pornografia e da prostituição (p. 184-185). Em particular, é um lucrativo nicho de mercado para cirurgiões, psicólogos e para a indústria farmacêutica, que ganha milhões com a venda de hormônios. Há riscos - físicos e psicológicos - associados às cirurgias e aos tratamentos hormonais. Também há uma parcela de transgêneros que se arrependem da mudança, o que "mina a ideia de que existe um tipo particular de pessoa que é genuína e essencialmente transgênero e pode ser identificada acuradamente por psiquiatras" (p. 72). Riscos e arrependimentos são, segundo Jeffreys, abafados para não desestabilizar o projeto da transgeneridade (e não afetar os negócios).

Uma última preocupação de Jeffreys é com os efeitos da transgeneridade sobre as mulheres, questão que ela desdobra em dois aspectos. Primeiro, a pressão para que as mulheres apoiem a opção de seus parceiros que decidem mudar de gênero, uma pressão que é quase inexistente para os homens na mesma posição. Mas uma mulher cujo marido decide se tornar mulher precisa redefinir a si mesma como lésbica, além de ver o orçamento doméstico ser dissipado em cirurgias, tratamentos hormonais, lingerie e maquiagem (p. 90). Quando é uma lésbica que decide se tornar homem, sua parceira, além de se ver subitamente engajada numa relação "heterossexual", é frequentemente constrangida a adotar comportamentos femininos estereotipados, a fim de que, por constraste, a "masculinidade" de sua parceira seja realçada (p. 120). São ônus impostos a essas mulheres, sem que elas participem da decisão que os acarreta. Espera-se delas o papel compassivo, tolerante e abnegado que sempre foi percebido, pelo feminismo, como opressivo e nefasto aos interesses das mulheres.

O segundo aspecto é como os transgêneros promovem a ocupação, por pessoas nascidas homens, de espaços que as mulheres conquistaram com sua luta. A começar pelos banheiros públicos femininos: Jeffreys lembra que a existência de sanitários para uso exclusivo das mulheres foi uma bandeira fundamental para garantir seu acesso à esfera pública (p. 154). Quando transgêneros não operados reivindicam utilizar banheiros ou saunas femininos, o resultado é que muitas mulheres se sentem constrangidas e param de usá-los, com prejuízo de sua possibilidade de participar do espaço público.

Há conflito também quanto à presença de transgêneros nos movimentos de mulheres, por vezes reivindicando posições de liderança. Independentemente das questóes de fundo, relativas à visão geral das relações de gênero que embasa a transgeneridade, uma pessoa que chegou à idade adulta como homem, eventualmente casou-se e teve filhos em relações heterossexuais, e em algum momento posterior descobre que quer ser mulher, não apresenta o conjunto de vivências que caracterizam a condição de mulher numa sociedade sexista. Logo, dificilmente pode ser porta-voz das mulheres e encontra-se deslocada nos espaços em que as mulheres buscam refletir autonomamente sobre sua própria experiência. "A teoria e a prática da transgeneridade", Jeffreys escreve, "contradizem a verdadeira base do feminismo [...], um movimento político baseado na experiência de pessoas que são mulheres, nasceram mulheres e foram criadas na casta sexual feminina" (p. 36).

Da forma como Jeffreys relata, há uma inconformidade, de parte da comunidade transgênero, quanto à permanência de espaços exclusivos para mulheres ou para lésbicas - que, no entanto, sempre foram cruciais para a emergência de uma consciência feminista. Ela descreve a ação continuada contra o Michigan Womyn's Music Festival, o importante encontro lésbico da América do Norte, alvo de invasões e de violentas campanhas de desmoralização 
(p. 168). A aceitação da presença de homens ou ex-homens, porém, desvirtuaria o sentido do festival. Para a autora, em suma, a transgeneridade é o cavalo de Troia do movimento feminista e lésbico.

Leitores sensíveis à temática certamente ficarão chocados com a forma pela qua Jeffreys iguala a transgerenidade a distúrbios bizarros de identidade, como aqueles em que pessoas desejam ter braços amputados ou, sem sofrer qualquer deficiência física, incorporam uma "identidade" paraplégica e desejam se tratadas como tal (p. 34-5). Para ela, no entanto a questão é mostrar que toda a diferença entre amputar genitais ou amputar um braço entre dizer que é mulher sendo homem ou dizer que é cadeirante tendo uso das pernas - reside na aceitação do gênero como realidade palpável, como uma essência à qual o corpo deve se adaptar.
O problema mais grave de Gender hurts parece ser outro. Jeffreys foca sua atenção no universo dos transgêneros de classe média, intelectualmente sofisticados e mesmo acadêmicos. Seu transgênero é um privilegiado que brinca de mudar de identidade e faz escolhas com grande liberdade. Uma realidade muito distante, por exemplo, de milhares de travestis no Brasil, que não têm acesso à escola ou ao mercado de trabalho, que sofrem cotidianamente as mais diversas formas de violência, incluindo uma altíssima taxa de homicídios, e que acabam condenadas à prostituição e à criminalidade. A crítica ao discurso da transgeneridade, que é necessária, não pode se descolar da defesa intransigente dos direitos dessa população.

Luis Felipe Miguel Universidade de Brasília, DF, Brasil

376 Estudos Feministas, Florianópolis, 24(1): 373-376, janeiro-abril/2016 